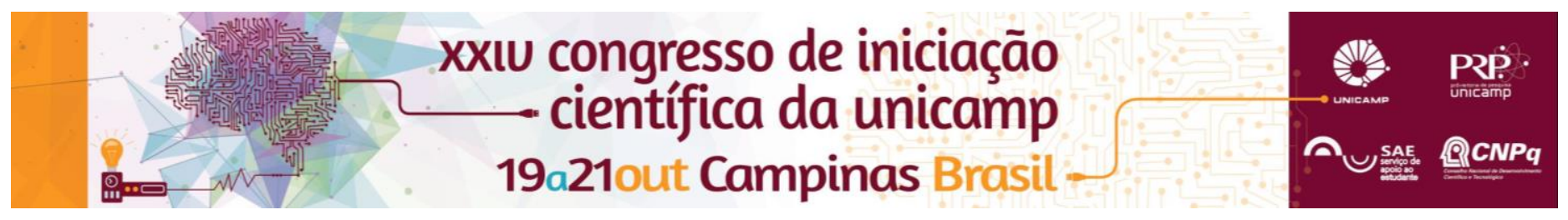

\title{
Indução de defesas em Asclepias curassavica (Apocynaceae: Asclepiadoideae) por herbívoros especialistas
}

\section{Verediana de Abreu*, José Roberto Trigo}

\begin{abstract}
Resumo
Asclepias curassavica é defendida quimicamente contra herbívoros pela presença de cardenolidas no látex e nas folhas, além de ser defendida fisicamente pelo látex. Larvas da borboleta especialista Danaus erippus induzem uma maior exsudação de látex, mas diminuem a concentração de cardenolidas nessa secreção. Em folhas, a herbivoria por $D$. erippus não induz cardenolidas. O afídeo especialista Aphis nerii não induz cardenolidas em folhas ou látex. A indução de é específica para cada tipo de herbívoro.
\end{abstract}

\section{Palavras-chave}

Aphis nerii, cardenolidas, Danaus erippus

\section{Introdução}

Plantas intensificam suas defesas em resposta ao ataque de herbívoros, em um processo definido como indução de defesas (Karban \& Baldwin 1997). Asclepias curassavica (Apocynaceae: Asclepiadoideae) é defendida quimicamente contra herbívoros pela presença de cardenolidas no látex e nas folhas, além de ser defendida fisicamente pelo látex. Entretanto as larvas mastigadoras da borboleta Danaus erippus (Nymphalidae: Danainae: Danaini) e os pulgões sugadores Aphis nerii (Hemiptera: Aphididae) se alimentam respectivamente das folhas e da seiva dessa planta. Ambos os herbívoros são especialistas e sequestram as cardenolidas em seus tecidos para a sua própria defesa. Nesse trabalho avaliamos a indução de cardenolidas e do látex pela ação dos dois herbívoros atuando separadamente e em conjunto.

\section{Resultados e Discussão}

Em relação ao látex, somente as larvas de $D$. erippus induziram uma maior exsudação; aproximadamente quatro vezes mais em relação ao controle (Fig. 1A). Aphis nerii ou as duas espécies atuando em conjunto não induziram latéx em relação ao controle (Fig. 1A). Em relação as cardenolidas no látex, a concentração diminuiu quando as plantas eram atacadas por larvas de $D$. erippus ou $D$. erippus juntamente com $A$. nerii (Fig. 1B). O afídeo sozinho não afetou a produção de cardenolidas no látex (Fig. 1B). As cardenolidas nas folhas não foram induzidas, nem diminuíram quando $A$. curassavica foi atacada pelos herbívoros isolados ou em conjunto (Fig. 1C).

Zalucki et al. (2001) demostraram que uma maior exsudação de látex em $A$. curassavica aumenta a mortalidade de larvas recém-nascidas de $D$. plexippus em $50 \%$ ao obstruir ou aprisionar suas peças bucais ou pernas, tornando-se uma defesa física eficaz contra esse tipo de herbívoro. Afídeos evitam os laticíferos das plantas devido a sua alimentação intercelular (Dussourd 1995). Portanto, acreditamos que $A$. curassavica investiria em látex como defesa contra $D$. erippus, mas não contra $A$. nerii.

Em relação as cardenolidas presentes no látex, levantamos a hipótese que as plantas reduziriam o investimento nessa defesa para tornar os herbívoros mais suscetíveis aos inimigos naturais pela falta da proteção química adquirida (Martel \& Malcolm 2004).

Apesar de não termos encontrado um aumento significativo das cardenolidas nas folhas, acreditamos que a indução seja um fenômeno que varia temporalmente. Em $A$. syriaca, o ataque por parte de $D$. plexippus aumentou a concentração de cardenolidas em até três vezes após 24 horas, com posterior declínio ao longo de seis dias (Malcolm \& Zalucki 1996). Possivelmente o mesmo poderia estar ocorrendo em $A$. curassavica, devido a duração do experimento.
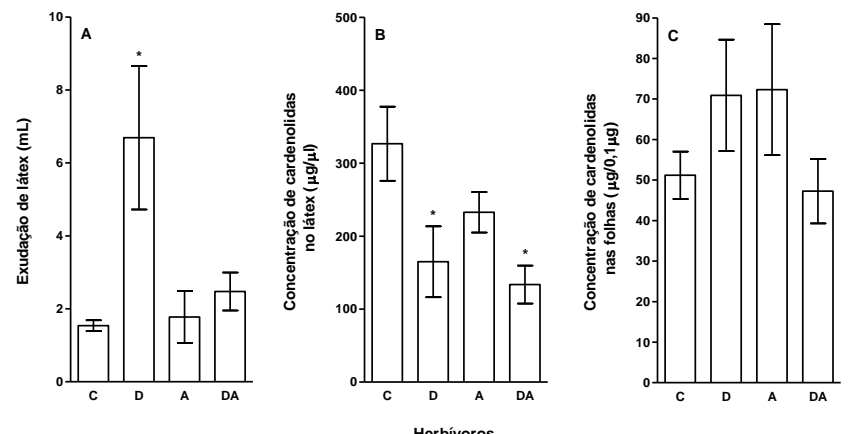

Figura 1. Defesas induzidas em látex e folhas de Asclepias curassavica por herbívoros especialistas $(C=$ Controle sem herbívoro, $\mathrm{D}=$ Danaus erippus, $\mathrm{A}=$ Aphis nerii e $\mathrm{DA}=D$. erippus $+A$. nerii). Asterisco representa diferença significativa $(p<0,05)$ do efeito do herbívoro em relação ao controle.

\section{Conclusões}

A indução das defesas é específica para cada herbívoro.

\section{Agradecimentos}

Agradecemos a FAPESP (2011/17708-0) e CNPq (306103/2013-3) pelo apoio financeiro.

Dussourd D (1995) Annals of the Entomological Society of America 88: 163-172.

Karban R, Baldwin (2007) Induced responses to herbivory. University of Chicago Press.

Malcolm SB, Zalucki MP (1996) Entomologia Experimentalis et Applicata 80: 193-196.

Martel JW, Malcolm SB (2004) Journal of Chemical Ecology 30: 545-561. 